\title{
Insight \\ Revealing the Organization of Complex Adaptive Systems through Multivariate Time Series Modeling
}

\author{
$\underline{\text { David G. Angeler }}^{1}, \underline{\text { Stina Drakare }}^{1}$, and $\underline{\text { Richard K. Johnson }}^{1}$
}

\begin{abstract}
Revealing the adaptive responses of ecological, social, and economic systems to a transforming biosphere is crucial for understanding system resilience and preventing collapse. However, testing the theory that underpins complex adaptive system organization (e.g., panarchy theory) is challenging. We used multivariate time series modeling to identify scale-specific system organization and, by extension, apparent resilience mechanisms. We used a 20-year time series of invertebrates and phytoplankton from 26 Swedish lakes to test the proposition that a few key-structuring environmental variables at specific scales create discontinuities in community dynamics. Cross-scale structure was manifested in two independent species groups within both communities across lakes. The first species group showed patterns of directional temporal change, which was related to environmental variables that acted at broad spatiotemporal scales (reduced sulfate deposition, North Atlantic Oscillation). The second species group showed fluctuation patterns, which often could not be explained by environmental variables. However, when significant relationships were found, species-group trends were predicted by variables (total organic carbon, nutrients) that acted at narrower spatial scales (i.e., catchment and lake). Although the sets of environmental variables that predicted the species groups differed between phytoplankton and invertebrates, the scale-specific imprints of keystone environmental variables for creating cross-scale structure were clear for both communities. Temporal trends of functional groups did not track the observed structural changes, suggesting functional stability despite structural change. Our approach allows for identifying scale-specific patterns and processes, thus providing opportunities for better characterization of complex adaptive systems organization and dynamics. This, in turn, holds potential for more accurate evaluation of resilience in disparate system types (ecological, social, economic).
\end{abstract}

Key Words: complex adaptive systems dynamics; complex adaptive systems organization; cross-scale structure; discontinuities; environmental variables; invertebrates; lakes; panarchy; phytoplankton; resilience; time series modeling

\section{INTRODUCTION}

Since Simon's (1973) seminal work about the organization of complex, hierarchical systems, ecological thinking has shifted from a small-scale view that characterized much ecology, to a multiscale and landscape view which recognizes that biotic and abiotic processes can develop selforganizing, mutually reinforcing relationships (Allen and Starr 1982). According to panarchy theory (Gunderson and Holling 2002), complex adaptive systems show cross-scale structure resulting from positive, self-reinforcing organization of scale-specific processes. These processes form adaptive cycles, whereby each cycle operates at distinct ranges of spatiotemporal scales. It is increasingly recognized that the organization of complex adaptive systems, including ecological, social, and economic systems, follows predictions of panarchy theory (Garmestani et al. 2009).

There is evidence about the existence of cross-scale structure in complex adaptive systems. For example, community ecologists have intensively studied discontinuities in body mass aggregations using different statistical methods (Stow et al. 2007). Body mass aggregations are conservative structures that are maintained even when communities are exposed to natural or anthropogenic disturbance (Havlicek and Carpenter 
2001); they have been found in a wide range of assemblages (Allen and Holling 2008). Several competing hypotheses, which emphasizes processes that operate from scales of local biological interactions to biome-scale processes, have been advanced to describe underlying causes of discontinuities or aggregation of body mass (Allen et al. 2006). However, these hypotheses are not mutually exclusive, because the imprints of processes predicted by each hypothesis may operate at discrete scales, from local to regional to biome, thus creating cross-scale structure and mutually reinforcing relationships (Allen et al. 2006). This complexity has so far limited the empirical evaluation of the dynamic behavior of complex adaptive systems.

Attempts have been made to increase our understanding of complex adaptive systems organization and dynamics using time series analyses (e.g., Garmestani et al. 2008, Wardwell and Allen 2009). For example, Gunderson et al. (2006) and Gunderson (2008) demonstrated for the Everglades (Florida, USA) that many hydrological variables were best explained by annual variability, while water flows and fire regimes varied at roughly decadal cycles. These authors also found discontinuities in the biomass aggregations of birds and spatial patterns of vegetation, but could not mechanistically relate structural discontinuities at the biological level to those in the landscape. Notwithstanding, the demonstration that key structuring processes, which organize this ecosystem, are separated by an order of magnitude highlights the presence of cross-scale structure and supports predictions made by panarchy theory.

Here we aim to find causal linkages between processes that operate at discrete landscape scales and their role in creating discontinuities at the biological level. We use ecological communities (lake phytoplankton and invertebrates) as models of complex adaptive systems and we use a novel multivariate time series modeling approach to explicitly address if processes that operate at different scales cause discontinuities in the dynamics of complex adaptive systems. The time series modeling approach used here extracts different temporal patterns of species groups from the whole community (Angeler et al. 2009). It generates patterns that allow the assessment of whether the communities organize in scale-specific regimes and form different species groups that are segregated along a one-dimensional (temporal) axis. The method has, therefore, the potential to detect discontinuities in the dynamic organization of communities and identify cross-scale structure from a temporal perspective. The method also permits the strength of each scale-specific pattern to be numerically quantified (Angeler et al. 2009) which allows us to examine the relative importance of individual scale-specific (species group) patterns to whole complex adaptive systems dynamics.

Once temporal patterns of different species groups (scales) are identified, correlations of species group trends revealed through the time series modeling with environmental variables provides the opportunity to assess scale-specific ecological footprints associated with community dynamics (for example, Holling 1992).

We tested two specific hypotheses: 1) Species groups within invertebrates and phytoplankton communities show different temporal patterns which are indicative of discontinuous temporal organization. The multivariate time series analysis was used to test this hypothesis. 2) The species groups are structured by different sets of environmental key variables. To test this proposition, modeled species group trends were correlated with environmental variables that act as surrogates of processes that in turn act at different spatiotemporal scales (e.g., trophic state conditions act as a local-scale measure, and climate variability acts as a regional factor). We also expected that community organization would be conservative; that is, both communities should show similar crossscale structure and organization regimes.

\section{METHODS}

\section{Study area}

In the late 1980s, Sweden initiated a long-term monitoring program of multiple habitats and trophic levels of lakes. Twenty-six lakes with the longest continuous time series were selected from the monitoring data for this study. These lakes were environmentally heterogeneous, spanning gradients in abiotic characteristics (Secchi depth 1.1 to 10.7 $\mathrm{m}$; water color $<0.01$ to $7.98 \pm \mathrm{mg} \mathrm{Pt} \mathrm{L}^{-1}$; $\mathrm{pH} 4.6$ to 7.3 , alkalinity $<0.01$ to $0.30 \mathrm{meq} \mathrm{L}^{-1}$; and lake size 0.11 to $5.43 \mathrm{~km}^{2}$; Appendix 1). Samples for water chemistry, phytoplankton and littoral invertebrate assemblages were collected over 20 years (19882007) from these lakes. Selected limnological 
variables and the location of these lakes are shown in Appendix 1; more information is available at the website of the Department of Aquatic Sciences and Assessment, Swedish University of Agricultural Sciences, http://www.slu.se/vatten-miljo.

\section{Sampling}

Data from surface water samples were selected from the sampling occasions when phytoplankton and benthic invertebrates were sampled, usually in August and October respectively, at a midlake station in each lake. Water was collected with a plexiglass sampler and kept cool during transport to the laboratory. Samples were analyzed for variables shown in Appendix 1. All physico-chemical analyses were conducted at the Department of Aquatic Sciences and Assessment, Swedish University of Agricultural Sciences following international (ISO) or European (EN) standards, when available (Wilander et al. 2003).

Phytoplankton was sampled by taking a water sample from the epilimnion using a 2-m-long plexiglass tube sampler and preserving it with Lugol's iodine-solution. Phytoplankton counts were made using an inverted light microscope and the modified Utermöhl technique commonly used in the Nordic countries (Olrik et al. 1989). Taxa were identified to the finest taxonomic unit possible (usually species), and species-specific biovolume measures were calculated using geometric formula. We also determined functional groups for phytoplankton (autotrophic, mixotrophic, and heterotrophic) following the classification scheme of Jansson et al. (1996). In 1992 enumeration of phytoplankton changed from counts of predominating taxa to counts of all species in a sample; hence phytoplankton counts before 1992 were not included in this study.

Benthic invertebrates were collected from windexposed, vegetation-free littoral habitats in late autumn (October to November). Five replicate samples were taken using standardized kick sampling with a hand net (0.5-mm mesh size). Each sample was taken by disturbing the bottom substratum for 20 seconds along a $1-\mathrm{m}$ stretch of the littoral region at a depth of about $0.5 \mathrm{~m}$; thus a total area of $1.25 \mathrm{~m}^{2}$ was sampled in each lake. Samples were preserved in $70 \%$ ethanol in the field and processed in the laboratory by sorting against a white background with $10 \mathrm{x}$ magnification.
Invertebrates were identified to the lowest taxonomic unit possible, generally to species level, and counted using dissecting and light microscopes. Functional groups (gatherers/collectors, parasites, wood-eating taxa, predators, miners, active and passive filter feeders, shredders, and grazers/ scrapers) were calculated using the Asterics 3.1.1. freeware (http://www.fliessgewaesserbewertung.de/ en/download/berechnung/) (IRV-Software, Vienna, Austria). This program calculates the percentage of functional groups in communities, based on specific codes associated with their component species. Each code links to autecological information of a species, which the program uses to automatically calculate functional groups.

\section{Statistical analyses}

\section{Detecting discontinuities and cross-scale structure in time series}

We used a relatively novel multivariate time series modeling approach which breaks down the overall temporal structure of communities into independent patterns shown by different groups of species that comprise a community (Angeler et al. 2009, 2010). It allows for identifying cross-scale structures in communities along a one-dimensional (temporal) axis that may arise due to dynamical organization of interacting abiotic and biotic factors. This method provides a powerful tool for studying complex adaptive systems because it has good statistical error properties (Angeler et al. 2009), which is a requirement for inferring the behavior of complex systems (Holling and Allen 2002). From the heuristic side, it permits the organization of groups of species within a community to be evaluated in different scaling regimes, and it permits the assessment of the degree by which environmental keystone variables mediate in this organization.

The method is based on redundancy analysis, where time is modeled with a principal coordinate of neighborhood matrices approach. In a first step, the analysis converts a time vector comprised of time steps (i.e., sampling years), 20 time steps in the case of invertebrates (1988-2007) and 16 time steps (sampling years) in the case of phytoplankton (1992-2007), in a series of principal coordinate of neighborhood matrices variables akin to a Fourier transform; that is, a number of different sine waves with different temporal frequencies are obtained through conversion of a single variable (i.e., the time 
vector). The number of obtained sine waves (or principal coordinate of neighborhood matrices variables) depends on the length of the time vector that comprises the study period; thus a total of 12 and 10 principal coordinate of neighborhood matrices variables were obtained for the invertebrate and phytoplankton analyses, respectively. Through a forward selection procedure, these principal coordinate of neighborhood matrices variables were related to the community data sets by means of redundancy analysis. The redundancy analysis retained significant principal coordinate of neighborhood matrices variables, and these were linearly combined in ways to extract temporal patterns from the species matrices. Species with similar temporal trends were identified through the analysis and merged into species groups. The significance of the temporal patterns of these species groups was tested by means of permutation tests. Significant species groups are associated with canonical axes; and, based on the number of significant canonical axes, the number of species groups with different temporal patterns can be deduced. The temporal patterns of species groups associated with each canonical axis are graphically shown in linearly combined score plots, which present the extracted temporal patterns of a species group based on significant, linearly combined, principal coordinate of neighborhood matrices variables. The importance of these temporal patterns was quantified, using adjusted $\mathrm{R}^{2}$ values of the canonical axes, and the species contributions to these patterns were assessed through correlation scores with the respective canonical axes. The overall temporal structure of the whole community could then be deduced from the number of significant canonical axes in the redundancy analysis models. All relevant steps in the analysis, from conversion of the linear time vector to principal coordinate of neighborhood matrices variables, and the identification of independent temporal patterns of species groups through redundancy analysis, were carried out with the quickPCNM (principal coordinate of neighborhood matrices) function implemented in the $\mathrm{R}$ 2.6.0 statistical software package (R Development Core Team 2008). Each lake analysis was based on phytoplankton biovolume data and invertebrate abundance data (both Hellinger-transformed), which comprised the dependent matrix.

\section{Identifying scale-specific drivers of patterns}

We used generalized linear models to explore relationships between the temporal patterns of each independent species group (identified by the time series analyses) within the phytoplankton and invertebrate assemblages and the environmental variables. We carried out separate analyses for each lake, using the linearly combined scores from each canonical axis as the dependent variable (i.e., the pattern that summarizes the temporal structure of a specific species group). We used the following as predictor variables: Secchi depth, water temperature, $\mathrm{pH}$, electrical conductivity, alkalinity, sulfate, ammonium, total phosphorus, total organic carbon concentrations, and water color. These variables influence communities at different spatiotemporal scales (e.g., catchment and lake - trophic state conditions, organic carbon; broad landscape scales - decreased sulfate deposition, the North Atlantic Oscillation) (NAO data obtained from Hurrell 2010). The calculated functional groups were used as predictors of change for assessing whether structural patterns of species group correlates with the variability of functional community attributes. Generalized linear models were estimated for each lake and species group per community (invertebrates and phytoplankton) and inference was based on a multimodel selection procedure based on information theoretic criteria (Burnham and Anderson 2002).

\section{RESULTS}

\section{Discontinuities and cross-scale structure in time series}

For invertebrates, the temporal trends of lake communities analyzed with the redundancy analysis-PCNM (principal coordinate of neighborhood matrices) approach revealed a significant temporal structure in all of the 26 lakes. Significant temporal structure was associated with the first two canonical axes, which captured the temporal trends of two independent species groups within the communities of all lakes. The first species group showed a pattern of long-term directional change that was evident in all lakes, and these trends explained on average over $50 \%$ of the total constrained variance in the models. Fig. 1 (left panels), which represents the linear combination scores of the principal coordinate of neighborhood matrices variables associated with canonical axes, summarizes the temporal patterns of this first species group in some lakes. The second species group included unimodal to bimodal fluctuation patterns without directional change over time (Fig. 1 right panels); these patterns explained 
Fig. 1. Temporal trends of species groups associated with redundancy analysis (RDA) axes 1 and 2 for invertebrates (1988-2007, full black lines) and phytoplankton (1992-2007, dotted grey lines) indicated by linear combination (lc) score plots. Shown are the overall trends (means \pm standard deviations) from lakes with significant temporal structure $(n=26$, invertebrates; $n=19$, phytoplankton) (A), and the trends in selected lakes (B).

A

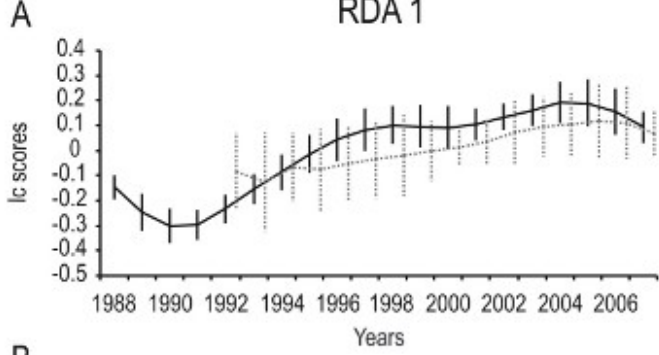

B
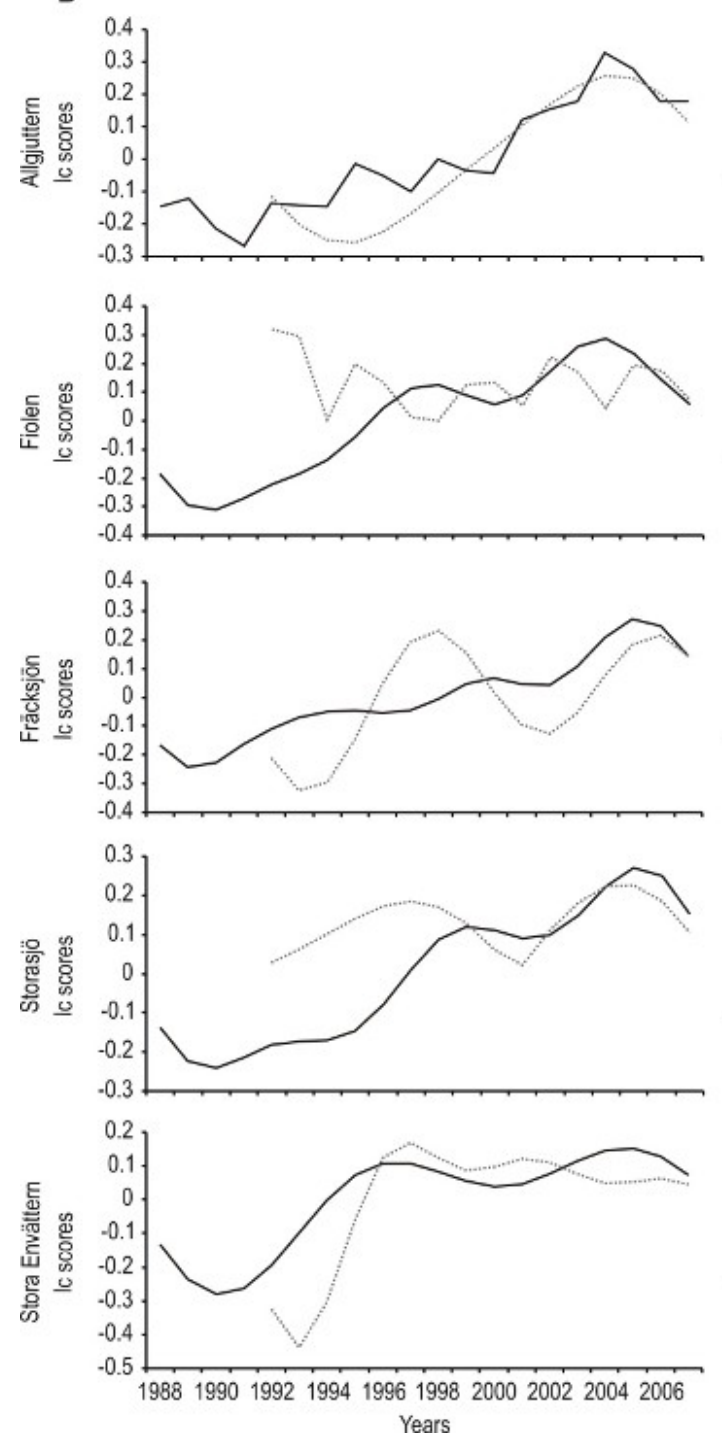

RDA 2
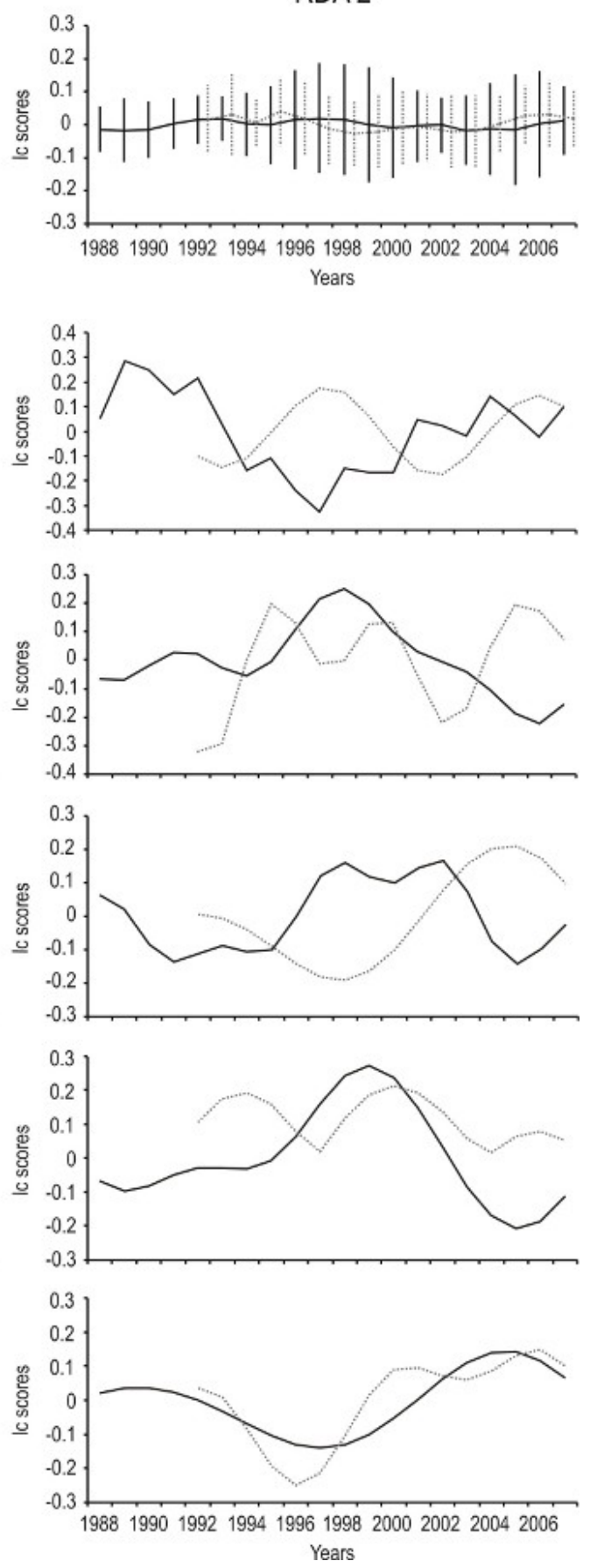
Fig. 2. Temporal trends of invertebrate and phytoplankton populations in selected lakes, which contributed to the temporal patterns associated with the canonical axes 1 and 2 in the redundancy analysis models. The species were chosen based on their highest loading to redundancy analysis axes. The numbers after the species names indicate whether the species loaded to redundancy analysis axis 1 or 2 .

\section{Macroinvertebrates}
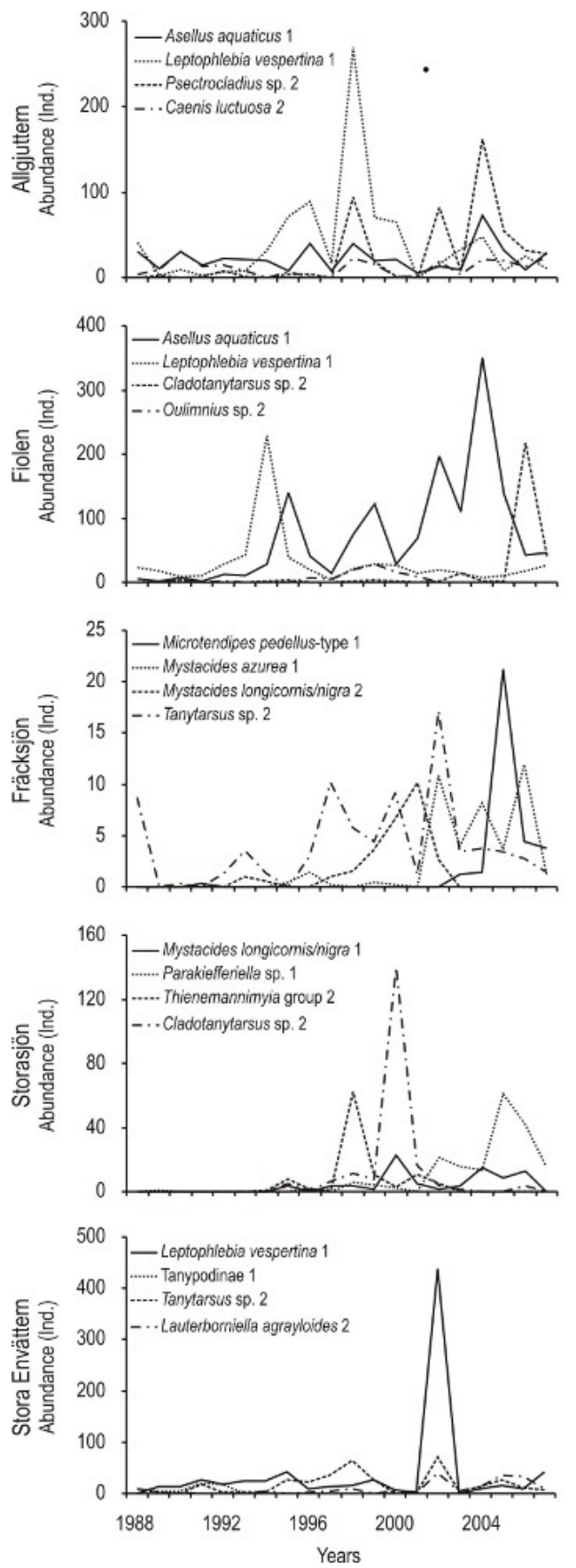

Phytoplankton
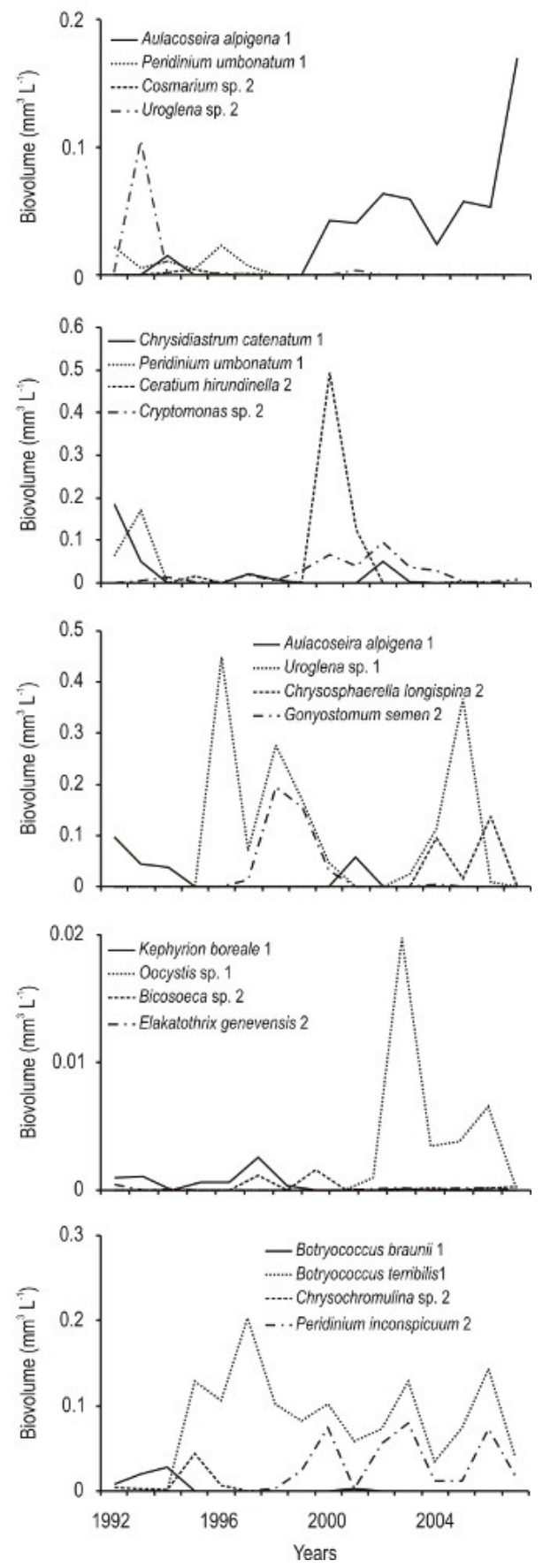
on average less than $30 \%$ of the adjusted variance in all invertebrate communities across lakes. Population trends of the two taxa, which contributed most importantly to the observed changes in both species groups, assessed by their loading to redundancy analysis axes, are shown in Fig. 2 for some lakes. The set of species contributing to these patterns and the strength and patterns of change for specific taxa (e.g., the mayfly Leptoblephia vespertina L.) differed among lakes.

For phytoplankton, a significant temporal structure was revealed in 19 of the 26 lakes. No significant temporal structure was found for lakes Abiskojaure, Bysjön, Härsvatten, Mäsen, Rotehogstjärnen, Storasjö, Sännen, and Övre Skärsjön. Two species groups with significantly different temporal structure were revealed, except in lakes Remmarsjön and Stor Tjulträsket, where only one significant species group was revealed. The temporal patterns associated with the first species group of phytoplankton explained on average over $60 \%$ of the total constrained variance in the models, while the patterns associated with the second species group explained on average about $30 \%$ of the adjusted variance across lakes. Contrary to the invertebrates, there was a less clear general trend of directional temporal change associated with the first species groups. Several lakes (e.g., Allgjuttern) revealed a directional change, while others showed variable degrees of short-term (e.g., Fiolen) to longer term fluctuations (e.g., Storasjö, Fräcksjön) (Fig. 1 left panels). The temporal patterns associated with the second species groups also showed substantial variability in fluctuation frequencies and amplitudes without a directional component of change over time (Fig. 1 right panels). Similar to the invertebrates, phytoplankton community change showed among-lake variability in terms of species contributions to change, as well as in terms of strengths and patterns of temporal change (Fig. 2).

\section{Scale-specific organization}

For the invertebrates, all lakes showed the clear imprints of sulfate concentrations in the dynamics of the first species group (except lakes Abiskojaure and Humsjön, where sulfate predicted the temporal patterns of the second species group), thus reflecting the imprints of broad-scale environmental variables (regionally reduced sulfate deposition) (Table 1). In addition to sulfate, the North Atlantic Oscillation winter index explained the temporal dynamics of the first species group in some lakes. In four lakes (Abiskojaure, Grissjön, Storasjö, Älgarydssjön) total phosphorus concentrations explained the temporal patterns of the second species group; otherwise the second species group was not significantly related to environmental variables in most lakes. Only in five lakes (Humsjön, Härsvatten, Jutsajaure, Skärgölen, Stora Envättern) were the imprints of broad-scale drivers (sulfate, North Atlantic Oscillation, temperature) visible in both species groups (Table 1).

Regarding the phytoplankton assemblages, the temporal dynamics of species groups were explained by variables that act at different spatiotemporal scales (sulfate, temperature, North Atlantic Oscillation, total organic carbon, total phosphorus) (Table 1). Almost all lakes captured the imprints of sulfate in one species group of phytoplankton (mainly the first species group). In Lake Brännträsket the combination of total organic carbon and total phosphorus separated species dynamics from those driven by sulfate. In lakes Jutsajaure and Tväringen, sulfate and temperature explained the temporal dynamics in one species group and total organic carbon explained the patterns in the other species group. Only in three lakes (Fräcksjön, Grissjön, Stensjön) were the imprints of North Atlantic Oscillation, sulfate, and temperature visible in both species groups (Table 1). As was the case for invertebrates, in many lakes the second species group within the phytoplankton communities was unrelated to environmental variables.

\section{Change in functional groups}

The trends of functional groups (percentages) of invertebrates and phytoplankton generally did not track the patterns of structural change across lakes (Fig. 3). Moreover, generalized linear models did not reveal significant relationships between the temporal changes at the structural level and the temporal trends of functional groups of invertebrates and phytoplankton.

\section{DISCUSSION}

We hypothesized that invertebrate and phytoplankton communities in lakes show cross-scale structure arising from the imprints of keystone environmental variables that act at specific scales in the landscape. 
Table 1. Summary of generalized linear model results. Shown are environmental variables that explained the temporal dynamics of different species groups (associated with canonical axes 1 and 2, respectively) revealed by time series modeling of invertebrates and phytoplankton. Degrees of freedom (df), F-ratios, and significance levels for each variable are given in parentheses $(* \mathrm{P}<0.05$; ** $\mathrm{P}<0.01, * * * \mathrm{P}<0.001)$. Abbreviations: TP, total phosphorus;, TOC, total organic carbon; Temp, temperature; $\mathrm{SO}_{4}$, sulfate concentration; NAO, North Atlantic Oscillation winter index; Ns, generalized linear model not significant; and ---, no significant temporal structure revealed by time series modeling.

\begin{tabular}{|c|c|c|c|c|}
\hline \multirow[b]{2}{*}{ Lakes } & \multicolumn{2}{|c|}{ Invertebrates (df 19) } & \multicolumn{2}{|c|}{ Phytoplankton (df 15) } \\
\hline & First species group & $\begin{array}{l}\text { Second species group } \\
\text { First species group } \\
\text { Second species group }\end{array}$ & & \\
\hline Mäsen & $-\mathrm{SO}_{4}(30.7 * * *)$ & Ns & --- & --- \\
\hline Stora Skärsjön & $-\mathrm{SO}_{4}(53.8 * * *)$ & Ns & $-\mathrm{SO}_{4}(18.6 * * *)$ & Ns \\
\hline Brännträsket & $-\mathrm{SO}_{4}(30.5 * * *)$ & Ns & $\begin{array}{c}\operatorname{TP}(6.1 *) \\
\operatorname{TOC}\left(7.1^{*}\right)\end{array}$ & $\mathrm{SO}_{4}\left(17.6^{* *}\right)$ \\
\hline Fräcksjön & $-\mathrm{SO}_{4}(63.1 * * *)$ & Ns & $-\mathrm{SO}_{4}(5.9 *)$ & $\begin{array}{l}\mathrm{SO}_{4}(11.4 * *) \\
\operatorname{TOC}(13.5 * *)\end{array}$ \\
\hline Stensjön & $-\mathrm{SO}_{4}(19.8 * * *)$ & Ns & $-\mathrm{NAO}\left(5.5^{*}\right)$ & $\begin{array}{l}\text { Temp }(8.2 *) \\
\operatorname{TOC}\left(6.0^{*}\right)\end{array}$ \\
\hline Tväringen & $-\mathrm{SO}_{4}(31.6 * * *)$ & Ns & TOC $\left(7.5^{*}\right)$ & $\begin{array}{c}\mathrm{SO}_{4}(23.6 * * *) \\
\mathrm{Temp}\left(7.3^{*}\right)\end{array}$ \\
\hline Skärgölen & $-\mathrm{SO}_{4}(20.7 * * *)$ & $\begin{array}{c}\mathrm{SO}_{4}\left(6.6^{*}\right) \\
\operatorname{Temp}\left(5.4^{*}\right)\end{array}$ & $\begin{array}{l}-\mathrm{SO}_{4}(69.4 * * *) \\
-\mathrm{NAO}\left(5.9^{*}\right)\end{array}$ & Ns \\
\hline Remmarsjön & $\begin{array}{l}-\mathrm{SO}_{4}\left(9.5^{* *}\right) \\
-\mathrm{NAO}\left(12.6^{* *}\right)\end{array}$ & Ns & $\begin{array}{l}-\mathrm{SO}_{4}\left(23.5^{* * *}\right) \\
\mathrm{TOC}\left(7.7^{*}\right)\end{array}$ & --- \\
\hline Stora Envättern & $\begin{array}{l}-\mathrm{SO}_{4}(22.7 * * *) \\
-\mathrm{NAO}(18.4 * * *)\end{array}$ & $\mathrm{SO}_{4}(5.8 *)$ & $\begin{array}{c}-\mathrm{NAO}\left(15.4^{* *}\right) \\
\text { TOC }\left(16.7^{* *}\right)\end{array}$ & $\mathrm{SO}_{4}(9.0 * *)$ \\
\hline Jutsajaure & $\begin{array}{l}-\mathrm{SO}_{4}(5.2 *) \\
-\mathrm{NAO}\left(10.5^{* *}\right)\end{array}$ & $\mathrm{SO}_{4}(5.7 *)$ & $\begin{array}{c}-\mathrm{SO}_{4}\left(17.0^{* *}\right) \\
\operatorname{Temp}\left(7.1^{*}\right)\end{array}$ & TOC $\left(15.3^{* *}\right)$ \\
\hline Fiolen & $\begin{array}{l}-\mathrm{SO}_{4}(46.8 * * *) \\
-\mathrm{NAO}\left(7.3^{*}\right)\end{array}$ & Ns & Ns & Ns \\
\hline Allgjuttern & $\begin{array}{l}-\mathrm{SO}_{4}\left(100.4^{* * * *}\right) \\
\operatorname{Temp}\left(5.0^{*}\right)\end{array}$ & Ns & $-\mathrm{SO}_{4}(53.1 * * *)$ & Ns \\
\hline Abiskojaure & $\mathrm{TP}\left(12.6^{* *}\right)$ & $\mathrm{SO}_{4}(53.1 * * *)$ & --- & --- \\
\hline Humsjön & $\begin{array}{l}-\operatorname{NAO}\left(6.2^{*}\right) \\
\text { TOC }\left(4.7^{*}\right)\end{array}$ & $\mathrm{SO}_{4}\left(10.3^{* *}\right)$ & $-\mathrm{SO}_{4}(31.0 * * *)$ & $\mathrm{TP}(4.9 *)$ \\
\hline Stor Tjulträsket & -NAO $\left(4.8^{*}\right)$ & Ns & Ns & --- \\
\hline Brunnsjön & $-\mathrm{SO}_{4}\left(26.6^{* * *}\right)$ & Ns & $-\mathrm{SO}_{4}(46.2 * * *)$ & Ns \\
\hline Bysjön & $-\mathrm{SO}_{4}(39.1 * * *)$ & Ns & --- & --- \\
\hline
\end{tabular}




\begin{tabular}{|c|c|c|c|c|}
\hline Hagasjön & $-\mathrm{SO}_{4}(20.0 * * *)$ & Ns & $\begin{array}{c}-\mathrm{SO}_{4}\left(20.3^{* * *}\right) \\
\text { TOC }\left(7.4^{*}\right)\end{array}$ & Ns \\
\hline Harasjön & $-\mathrm{SO}_{4}(62.3 * * *)$ & Ns & $\begin{array}{c}-\mathrm{SO}_{4}\left(11.3^{* *}\right) \\
\mathrm{TOC}\left(6.7^{*}\right)\end{array}$ & Ns \\
\hline Sännen & $-\mathrm{SO}_{4}(30.6 * * *)$ & Ns & --- & --- \\
\hline Övre Skärsjön & $-\mathrm{SO}_{4}(51.8 * * *)$ & Ns & --- & --- \\
\hline Grissjön & $-\mathrm{SO}_{4}(43.8 * * *)$ & $\mathrm{TP}(15.4 * *)$ & $-\mathrm{SO}_{4}\left(40.6^{* * *}\right)$ & Temp $\left(7.7^{*}\right)$ \\
\hline Storasjö & $-\mathrm{SO}_{4}(72.9 * * *)$ & $\mathrm{TP}\left(8.5^{* *}\right)$ & Ns & $\mathrm{SO}_{4}(5.0 *)$ \\
\hline Rotehogstjärnen & $\begin{array}{l}-\mathrm{SO}_{4}\left(25.8^{* * *}\right) \\
-\mathrm{NAO}(19.4 * * *)\end{array}$ & Ns & --- & --- \\
\hline Älgarydssjön & $\begin{array}{l}-\mathrm{SO}_{4}(29.0 * * *) \\
-\mathrm{NAO}\left(19.8^{* * *}\right)\end{array}$ & $\mathrm{TP}(9.7 * *)$ & $-\mathrm{SO}_{4}(33.8 * * *)$ & Ns \\
\hline Härsvatten & $\begin{array}{l}-\mathrm{SO}_{4}\left(9.4^{* *}\right) \\
-\mathrm{NAO}\left(13.5^{* *}\right)\end{array}$ & $\begin{array}{l}\mathrm{SO}_{4}(17.8 * * *) \\
\mathrm{Temp}(15.2 *)\end{array}$ & --- & --- \\
\hline
\end{tabular}

Consistent with predictions made by panarchy theory (Gunderson and Holling 2002), and supporting our hypotheses, the multivariate time series modeling technique resolved cross-scale structure in the invertebrate and phytoplankton assemblages in the form of two species groups which were, with a few exceptions, consistently found across all lakes. The species groups identified in the redundancy analyses showed significantly different temporal patterns, suggesting that the groups were arranged in self-organizing and mutually reinforcing regimes. The generalized linear models identified environmental drivers of the temporal dynamics of these species groups (see below), which provided further support for the hypothesis that only a few keystone variables that act at specific scales steer ecological patterns (Holling 1992). While generalized linear modeling was useful for finding scale-specific environmental associations, we acknowledge that more complex modeling techniques (i.e., generalized additive models) that account for nonlinear relationships and non-Gaussian error distributions could further fine tune associations between environmental variables and species group trends.

Several competing hypotheses have been advanced for explaining the origin of cross-scale structure in complex systems. Regarding ecological communities, hypotheses emphasizing energetic, phylogenetic, biogeographical, and textural landscape aspects, and community interactions have been emphasized to describe underlying causes of discontinuities or aggregation of body mass (Holling 1992, Allen et al. 2006, Scheffer and van Nes 2006). Allen et al. (2006) noted that these hypotheses are not mutually exclusive because they can make useful predictions at different spatial or temporal scales. For example, community interaction hypotheses apply to spatially and temporally proximate interactions among species residing within local landscapes. Textural discontinuity and biogeographical hypotheses apply over regional spatial and paleoecological temporal scales, and phylogenetic and energetic hypotheses apply most appropriately over spatially broad domains with slow dynamics. The results of our study support this notion, and provide further support that the imprints of scale-specific processes are captured at specific scales (species groups) within ecological systems. This similarity among studies is remarkable because our research approach, using time series modeling of entire communities, differs from previous research based on other methodologies. Much of the research focusing on complex adaptive systems organization is based on a quantitative evaluation of discontinuity by means of, for example, the gap rarity index, hierarchical cluster analyses, classification and regression trees, and the Bayesian implementation of classification and regression trees (Stow et al. 2007). These methods have been commonly applied for analyzing discontinuities in ecological data (fore xample, body mass aggregations; Allen and Holling 2008) or in urban and economic systems 
Fig. 3. Temporal trends of functional groups of invertebrate and phytoplankton communities. Shown are the overall trends (means \pm standard deviations) from lakes with significant temporal structure $(\mathrm{n}=26$, invertebrates; $\mathrm{n}=19$, phytoplankton) (A), and the trends in selected lakes (B).

A

Macroinvertebrates

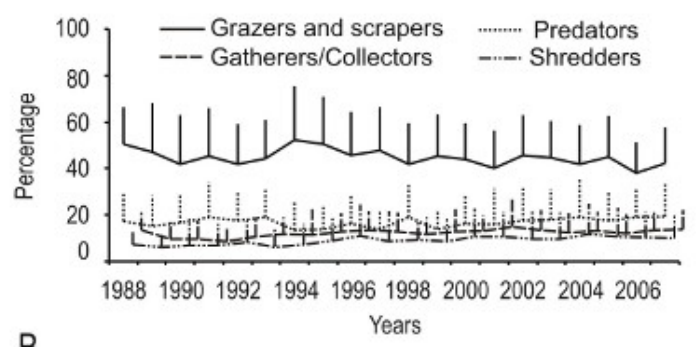

B
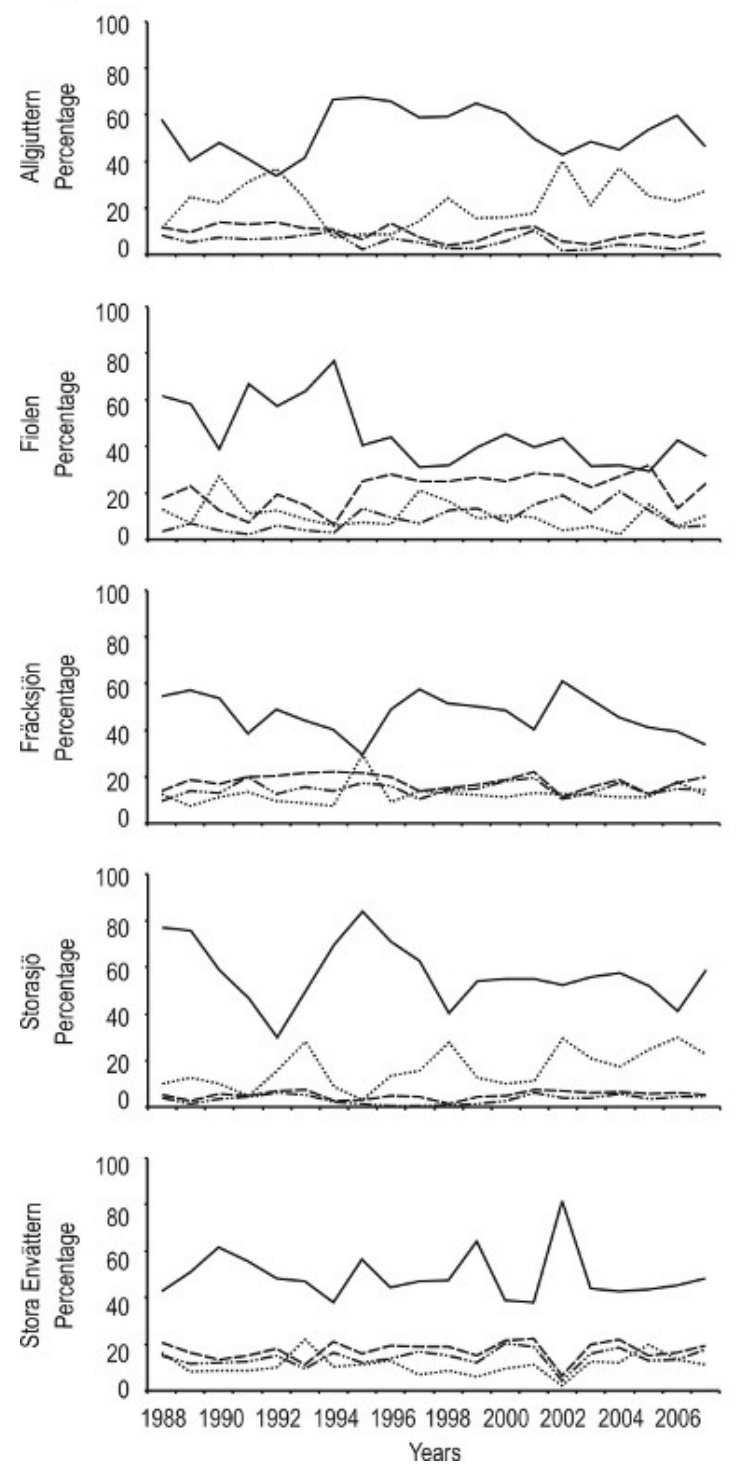

Phytoplankton
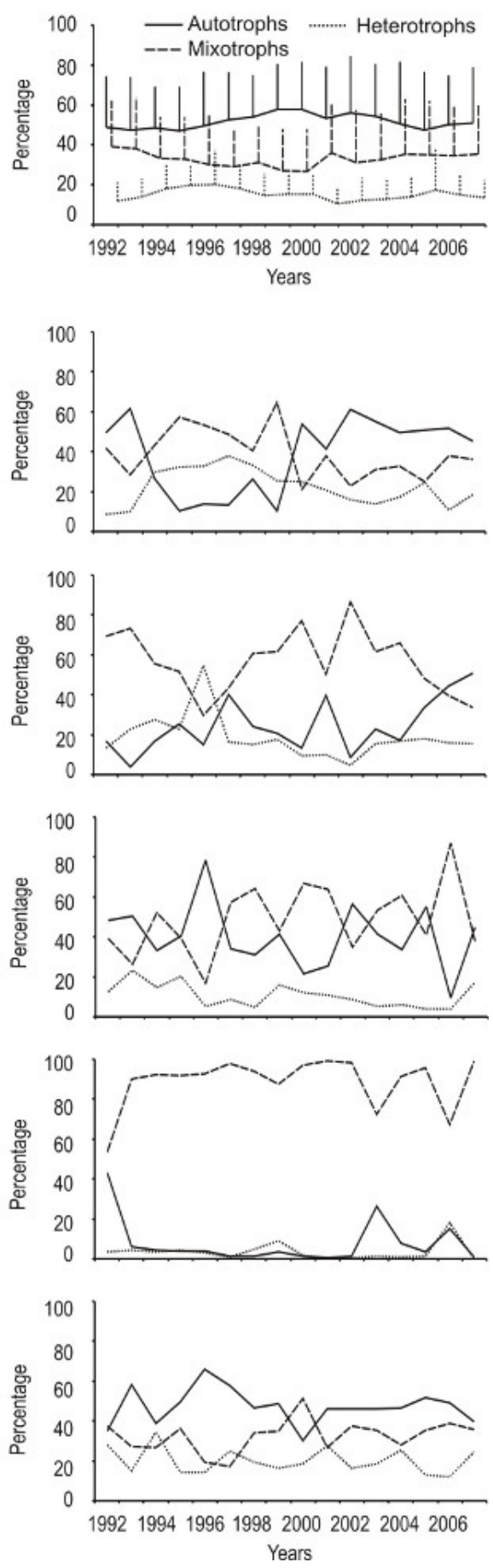
(Garmestani et al. 2007, 2009). While useful, these methods provide only a static picture of cross-scale structure, without allowing for making temporally explicitly inference about the underlying cause of structural organization. An advantage of the time series modeling used here, relative to the other methods, is the possibility of determining discontinuity and cross-scale structure while retaining the taxonomic information needed to explain dynamic patterns of change. Thus, the strength of multivariate time series modeling of complex adaptive systems organization is that it allows for determining cross-scale structure and temporal dynamics in a synthetic analysis, which can then be linked to patterns of environmental change.

The generalized linear modeling results show that species groups are predicted by environmental variables that act at different spatiotemporal scales. The importance of regionally operating variables on community dynamics (e.g., the North Atlantic Oscillation) has been demonstrated (Ottersen et al. 2001). Also the imprints of sulfate reflect broadscale environmental variability. International policy was implemented in the second half of the last century to reduce the emission of acidifying compounds to the atmosphere and to counteract the negative ecological effects of cultural acidification (Stoddard et al. 1999). This finding highlights the importance of anthropogenic consequences in regulating the dynamic organization of lake communities. It also shows a linkage between social and ecological systems, and supports the notion that in combined social, economic, and ecological panarchies, the socioeconomic factors can influence ecological processes (Leuteritz and Ekiba 2008).

Total organic carbon explained species group dynamics of phytoplankton but not that of invertebrates, thus highlighting taxon-specific differences in the creation of cross-scale structure, which may be mediated through differences in life history traits. This finding supports Holling's (1992) textural discontinuity hypothesis, which predicts that discontinuities in biological assemblages arise from taxon-specific differences in the scale-specific exploitation of their environment. Organic carbon mediates underwater light climate and conditions of dissolved nutrients in the water column (Keskitalo and Eloranta 1999), and may therefore have a more important direct effect on phytoplankton through interference with photosynthetic activity, compared to heterotrophic particle-feeding invertebrates.
Despite environmental variables having scalespecific imprints on the dynamics of species groups within invertebrates and phytoplankton, there were also species groups in both communities that were not related to abiotic variables. This suggests that our sampling was too coarse for detecting smallscale patterns. These small-scale patterns may be associated either with other environmental variables or with landscape structures, or, alternatively, with biological interactions, including the complex interplay of priority effects, resource constraints, disturbance responses, competition and predation regimes, and chance events. Although the relevance of biological interactions cannot be evaluated with the present data set, previous research has demonstrated their importance for shaping discontinuity in ecological systems (Roughgarden 1998, Allen et al. 2006, Scheffer and van Nes 2006).

Finally, we highlight the importance of cross-scale structure for mediating resilience in complex systems (e.g., Peterson et al. 1998, Wardwell et al. 2008, Angeler et al. 2010). Functional group attributes were not correlated with the structural variability observed in the time series of independent species groups. This suggests that both invertebrates and phytoplankton communities in boreal lakes can be resilient to environmental change. Considering that the emergent structural and functional attributes mediated by communities indicate ecosystem processes (Allen et al. 2005), our results would suggest that boreal lakes, and the ecosystem services they provide to humans and wildlife, could resist some of the threats arising from global change in the future. Nonetheless, it is critical to understand the roots of this apparent resilience in order to avoid catastrophic consequences when a resilience threshold is passed and systems collapse. Our approach for assessing system organization allows for revealing scale-specific ecological patterns and processes, and their ecological importance can be numerically quantified. This provides opportunities for better understanding the scale-specific imprints of human actions in the environment, for assessing resilience, and for taking management action in times of fast transformations of our biosphere. The multivariate time series modeling approach used in this study may also be fruitfully applied to increase our understanding of the dynamic organization of other complex adaptive systems, including other ecological, social, and economic systems. 
Responses to this article can be read online at:

http://www.ecologyandsociety.org/voll6/iss3/art5/responses/

\section{Acknowledgments:}

The data used for this study form part of a long-term monitoring program financed by the Swedish Environmental Protection Agency. Financial support from the European Union 7th Framework Project REFRESH under contract no. 244121 is also acknowledged. Special thanks to Craig Allen, the anonymous reviewers, and the Editor for helpful comments on previous manuscript versions.

\section{LITERATURE CITED}

Allen, C.R., A.S. Garmestani, T.D. Havlicek, P.A. Marquet, G.D. Peterson, C. Restrepo, C.A. Stow, and B.E. Weeks. 2006. Patterns in body mass distributions: sifting among alternative hypotheses. Ecology Letters 9:630-643. http://dx.doi.org/10.1111/ j.1461-0248.2006.00902.x

Allen, C.R., L. Gunderson, and A.R. Johnson. 2005. The use of discontinuities and functional groups to assess relative resilience in complex systems. Ecosystems 8:958-966. http://dx.doi.org/10.1007/s1 0021-005-0147-X

Allen, C.R., and C.S. Holling. 2008. Discontinuities in ecosystems and other complex systems. Columbia University Press, New York, USA.

Allen, T. F. H., and T. B. Starr. 1982. Hierarchy: perspectives for ecological complexity. Chicago University Press, Chicago, Illinois, USA.

Angeler, D. G., C. Trigal, S. Drakare, R .K. Johnson, and W. Goedkoop. 2010. Identifying resilience mechanisms to recurrent ecosystem perturbations. Oecologia 164:231-241. http://dx.doi.org/10.1007/ s00442-010-1640-2

Angeler, D.G., O. Viedma, and J. M. Moreno. 2009. Statistical performance and information content of time lag analysis and redundancy analysis in time series modeling. Ecology 90:3245-3257. http://dx.d oi.org/10.1890/07-0391.1

Burnham, K. P., and D. R. Anderson. 2002. Model selection and multimodel inference: a practical information-theoretic approach, second edition. Springer, New York, USA.

Garmestani, A. S., C. R. Allen, and K. M. Bessey. 2008. Discontinuities in urban systems: comparison of regional city size structure in the United States. Pages 136-154 in C. R. Allen and C. S. Holling, editors. Discontinuities in ecosystems and other complex systems. Columbia University Press, New York, USA.

Garmestani, A. S., C. R. Allen, C. M. Gallagher, and J. D. Mittelstaedt. 2007. Departures from Gibrat's Law, discontinuities and city size distributions. Urban Studies 44:1997-2007. http://d x.doi.org/10.1080/00420980701471935

Garmestani, A. S., C. R. Allen, and L. Gunderson. 2009. Panarchy: discontinuities reveal similarity in the dynamic system structure of ecological and social systems. Ecology and Society 14(1):15. [online] URL: http://www.ecologyandsociety.org/vol14/ iss1/art15

Gunderson, L. H. 2008. Biophysical discontinuities in the Everglades ecosystem. Pages 83-100 in C. R. Allen and C. S. Holling, editors. Discontinuities in ecosystems and other complex systems. Columbia University Press, New York, USA.

Gunderson, L., C. R. Allen, and D. Wardwell. 2006. Temporal scaling in complex systems: resonant frequencies and biotic variability. Pages 78-89 in J. A. Bissonette and I. Storch, editors. Temporal dimensions of landscape ecology. Springer, New York, USA.

Gunderson, L. H., and C. S. Holling. 2002. Panarchy: understanding transformations in human and natural systems. Island Press, Washington D.C., USA.

Havlicek, T., and S. R. Carpenter. 2001. Pelagic species size distributions in lakes: are they discontinuous? Limnology and Oceanography 46:1021-1033.

Holling, C. S. 1992. Cross-scale morphology, geometry and dynamics of ecosystems. Ecological Monographs 62:447-502.

Holling, C. S., and C. R. Allen. 2002. Adaptive inference for distinguishing credible from incredible patterns in nature. Ecosystems $5: 319-328$. 
Hurrell, J. 2010. Climate indices, introduction to NAO indices, winter (Dec-Mar) station based NAO index. National Council for Atmospheric Research, Earth System Laboratory, Climate and Global Dynamics, Boulder, Colorado, USA. [online] URL: http://www.cgd.ucar.edu/cas/jhurrell/nao.stat.winter. html.

Jansson, M., P. Blomqvist, A. Jonsson, and A. K. Bergström. 1996. Nutrient limitation of bacterioplankton, autotrophic and mixotrophic phytoplankton, and heterotrophic nanoflagellates in Lake Örträsket. Limnology and Oceanography 41:1552-1559.

Keskitalo, J., and P. Eloranta. 1999. Limnology of humic waters. Backhuys Publishers, Leiden, The Netherlands.

Leuteritz, T. E. J., and H. R. Ekiba. 2008. Not all roads lead to resilience: a complex systems approach to the comparative analysis of tortoises in arid ecosystems. Ecology and Society 13(1). [online] URL: http://www.ecologyandsociety.org/vol13/ iss1/art1/

Olrik, K. P., P. Blomqvist, P. Brettum, G. Cronberg, and P. Eloranta. 1989. Methods for quantitative assessment of phytoplankton in freshwaters, part I. Swedish Environmental Protection Agency, Stockholm, Sweden.

Ottersen, G., B. Planque, A. Belgrano, E. Post, P.C. Reid, and N. C. Stenseth. 2001. Ecological effects of the North Atlantic Oscillation. Oecologia 128:1-14.

Peterson, G. D., C. R. Allen, and C. S. Holling. 1998. Ecological resilience, biodiversity, and scale. Ecosystems 1:6-18.

R Development Core Team. 2008. $R$ : a language and environment for statistical computing. $\mathrm{R}$ Foundation for Statistical Computing, Vienna, Austria.

Roughgarden, J. 1998. Primer of ecological theory. Prentice Hall, Upper Saddle River, New Jersey, USA.

Scheffer, M., and E. van Nes. 2006. Self-organized similarity, the evolutionary emergence of groups of similar species. Proceedings of the National Academy of Sciences 103:6230-6235.
Simon, H. A. 1973. The organization of complex systems. Pages 1-27 in H. H. Pattee, editor. Hierarchy theory: the challenge of complex systems. George Braziller, New York, USA.

Stoddard, J. L., D. S. Jeffries, A. Lukewille, T. A. Clair, P. J. Dillon, C. T. Driscoll, M. Forsius, M. Johannessen, J. S. Kahl, J. H. Kellogg, A. Kemp, J. Mannio, D. T. Monteith, P. S. Murdoch, S. Patrick, A. Rebsdorf, B. L. Skjelkvåle, M. P. Stainton, T. Traaen, H. van Dam, K. E. Webster, J. Wieting, and A. Wilander. 1999. Regional trends in aquatic recovery from acidification in North America and Europe. Nature 401:575-578.

Stow, C., C. R. Allen, and A. H. Garmestani. 2007. Evaluating discontinuities in complex systems: toward quantitative measures of resilience. Ecology and Society 12(1):26. [online] URL: http://www.ec ologyandsociety.org/vol12/iss1/art26/

Wardwell, D., and C. R. Allen. 2009. Variability in population abundance is associated with thresholds between scaling regimes. Ecology and Society 14 (2):42. [online] URL: http://www.ecologyandsociety. org/vol14/iss2/art42/

Wardwell, D. A., C. R. Allen, G. D. Peterson, and A. J. Tyre. 2008. A test of the cross-scale resilience model: functional richness in Mediterraneanclimate ecosystems. Ecological Complexity $5: 165-182$.

Wilander, A., R. K. Johnson, and W. Goedkoop. 2003. Riksinventering 2000. En synoptisk studie av vattenkemi och bottenfauna $i$ svenska sjöar och vattendrag. Institutionen för Miljöanalys, Sveriges Lantbruksuniversitet, Uppsala, Sweden. 


\section{Appendix 1:}

Map of Sweden with location of lakes and table of water quality characteristics.

Figure 1: Map of Sweden showing the location of study lakes. See Table 1 for lake names.

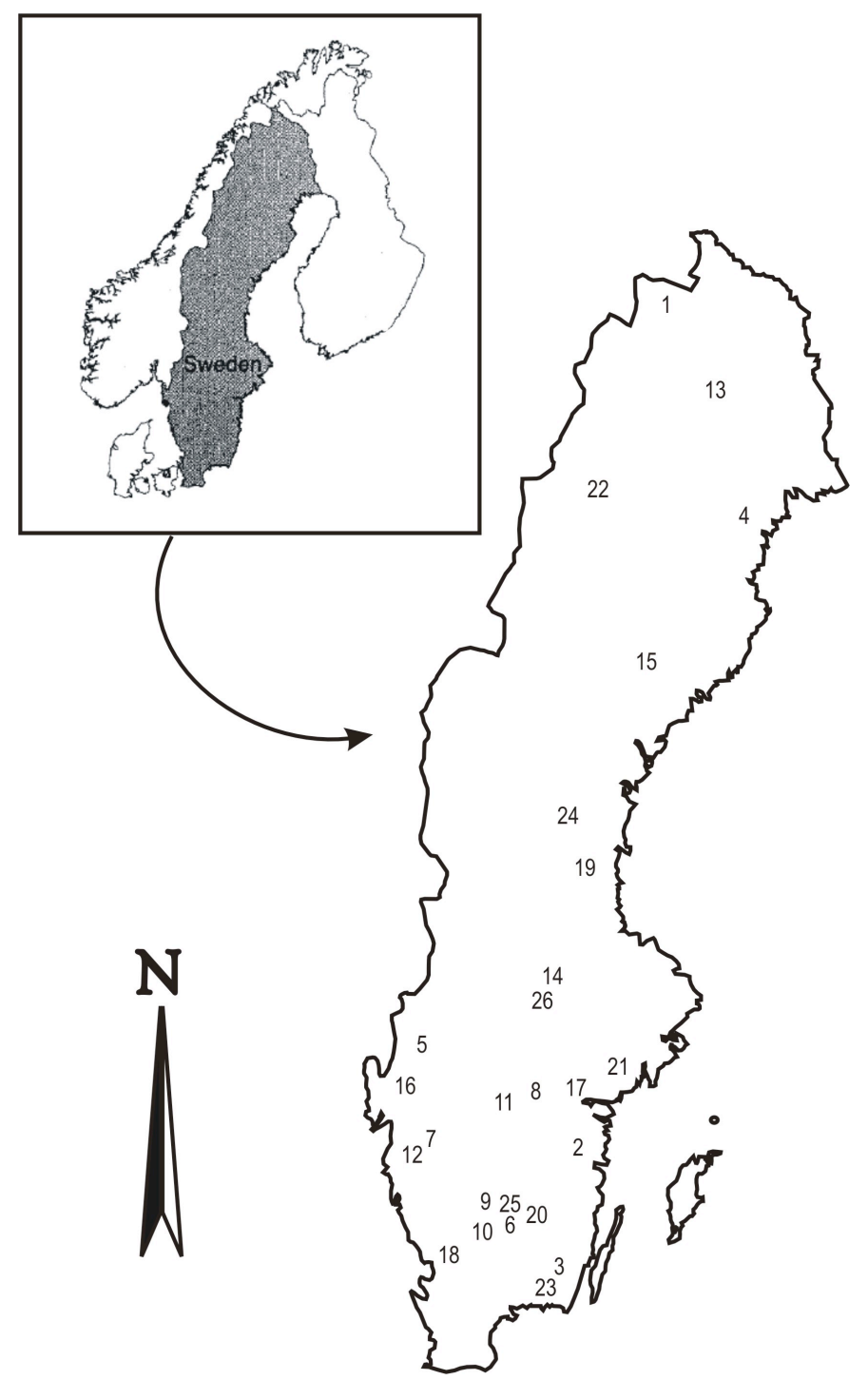


Table 1: Geographical position and limnological variables of study lakes. Shown are the means \pm standard deviations between 1988 and 2007 based on a yearly summer sample $(n=20)$. The number below each lake name makes reference to the lake position in Figure 1.

\begin{tabular}{|c|c|c|c|c|c|c|c|c|c|c|c|c|}
\hline Lake & $\begin{array}{l}\text { Coord. } \\
\text { (Long. } \\
\text {, Lat.) }\end{array}$ & $\begin{array}{l}\text { Lake } \\
\text { size } \\
\left(\mathrm{km}^{2}\right)\end{array}$ & $\begin{array}{l}\text { Secchi } \\
\text { depth } \\
\text { (m) }\end{array}$ & $\begin{array}{l}\text { Water } \\
\text { temp. } \\
\left({ }^{\circ} \mathrm{C}\right)\end{array}$ & $\mathrm{pH}$ & $\begin{array}{l}\text { Electr. } \\
\text { cond. } \\
\left(\mathrm{mS} \mathrm{cm} \mathrm{cm}^{-1}\right)\end{array}$ & $\begin{array}{l}\text { Alkalinity } \\
\text { (meq L-1) }\end{array}$ & $\begin{array}{l}\mathrm{SO}_{4} \\
\left(\mathrm{meq} \mathrm{L}^{-1}\right)\end{array}$ & $\begin{array}{l}\mathrm{NH}_{4}-\mathrm{N} \\
\left(\mu g \mathrm{~L}^{-1}\right)\end{array}$ & $\begin{array}{l}\text { Total P } \\
\left(\mu \mathrm{L} \mathrm{L}^{-1}\right)\end{array}$ & $\begin{array}{l}\text { Water color } \\
\text { (mg Pt L-1) }\end{array}$ & $\begin{array}{l}\text { TOC } \\
\left(\mathrm{mg} \mathrm{L}^{-1}\right)\end{array}$ \\
\hline $\begin{array}{l}\text { Abiskojaure } \\
1\end{array}$ & $\begin{array}{l}18.79 \\
68.36\end{array}$ & 2.84 & $10.3 \pm 1.3$ & $7.7 \pm 1.7$ & $7.2 \pm 0.1$ & $3.2 \pm 0.5$ & $0.19 \pm 0.03$ & $0.07 \pm 0.02$ & $6.0 \pm 4.1$ & $4.9 \pm 3.2$ & $<0.01 \pm 0.05$ & $1.4 \pm 0.7$ \\
\hline $\begin{array}{l}\text { Allgjuttern } \\
2\end{array}$ & $\begin{array}{l}16.10 \\
57.95\end{array}$ & 0.19 & $6.1 \pm 1.0$ & $15.0 \pm 2.5$ & $6.7 \pm 0.1$ & $5.0 \pm 0.5$ & $0.07 \pm 0.01$ & $0.19 \pm 0.03$ & $7.7 \pm 5.1$ & $7.8 \pm 4.5$ & $0.62 \pm 0.23$ & $7.4 \pm 0.8$ \\
\hline $\begin{array}{l}\text { Brunnsjön } \\
3\end{array}$ & $\begin{array}{l}15.83 \\
57.51\end{array}$ & 0.11 & $1.8 \pm 0.9$ & $9.4 \pm 2.6$ & $5.5 \pm 0.2$ & $6.7 \pm 1.2$ & $<0.01 \pm 0.02$ & $0.25 \pm 0.09$ & $38.8 \pm 12.6$ & $11.8 \pm 4.5$ & $7.36 \pm 3.15$ & $19.0 \pm 6.2$ \\
\hline $\begin{array}{l}\text { Brännträsket } \\
4\end{array}$ & $\begin{array}{l}17.04 \\
59.38\end{array}$ & 0.85 & $2.9 \pm 0.5$ & $10.9 \pm 2.8$ & $6.8 \pm 0.2$ & $3.1 \pm 0.2$ & $0.12 \pm 0.02$ & $0.07 \pm 0.02$ & $10.2 \pm 4.5$ & $9.4 \pm 2.1$ & $2.06 \pm 0.80$ & $9.4 \pm 1.8$ \\
\hline $\begin{array}{l}\text { Bysjön } \\
5\end{array}$ & $\begin{array}{l}18.25 \\
59.59\end{array}$ & 1.23 & $3.1 \pm 0.5$ & $9.6 \pm 2.8$ & $6.6 \pm 0.1$ & $4.9 \pm 0.6$ & $0.10 \pm 0.01$ & $0.11 \pm 0.03$ & $16.6 \pm 7.4$ & $9.9 \pm 2.7$ & $0.66 \pm 0.30$ & $6.8 \pm 0.3$ \\
\hline $\begin{array}{l}\text { Fiolen } \\
6\end{array}$ & $\begin{array}{l}14.53 \\
57.08\end{array}$ & 1.65 & $5.2 \pm 1.1$ & $9.9 \pm 2.2$ & $6.5 \pm 0.2$ & $5.7 \pm 0.7$ & $0.06 \pm 0.02$ & $0.18 \pm 0.05$ & $14.8 \pm 5.1$ & $11.3 \pm 3.6$ & $0.58 \pm 0.34$ & $7.2 \pm 3.1$ \\
\hline $\begin{array}{l}\text { Fräcksjön } \\
7\end{array}$ & $\begin{array}{l}12.18 \\
58.15\end{array}$ & 0.28 & $3.1 \pm 0.6$ & $10.5 \pm 1.9$ & $6.3 \pm 0.1$ & $7.3 \pm 1.4$ & $0.07 \pm 0.01$ & $0.16 \pm 0.06$ & $17.3 \pm 6.7$ & $9.4 \pm 4.0$ & $1.93 \pm 0.69$ & $9.2 \pm 2.3$ \\
\hline $\begin{array}{l}\text { Grissjön } \\
8\end{array}$ & $\begin{array}{l}15.15 \\
58.76\end{array}$ & 0.23 & $2.5 \pm 0.7$ & $8.1 \pm 1.7$ & $5.6 \pm 0.2$ & $3.5 \pm 0.6$ & $0.01 \pm 0.01$ & $0.13 \pm 0.03$ & $22.5 \pm 8.6$ & $7.9 \pm 2.7$ & $1.93 \pm 0.64$ & $9.6 \pm 1.7$ \\
\hline $\begin{array}{l}\text { Hagasjön } \\
9\end{array}$ & $\begin{array}{l}13.71 \\
57.34\end{array}$ & 0.12 & $2.7 \pm 0.6$ & $9.4 \pm 1.9$ & $6.3 \pm 0.2$ & $5.1 \pm 0.5$ & $0.07 \pm 0.02$ & $0.13 \pm 0.03$ & $34.8 \pm 22.7$ & $9.1 \pm 3.9$ & $1.78 \pm 1.05$ & $8.6 \pm 1.9$ \\
\hline $\begin{array}{l}\text { Harasjön } \\
10\end{array}$ & $\begin{array}{l}13.58 \\
57.01\end{array}$ & 0.59 & $1.1 \pm 0.6$ & $8.8 \pm 0.2$ & $5.3 \pm 0.3$ & $5.0 \pm 0.8$ & $<0.01 \pm 0.01$ & $0.12 \pm 0.05$ & $38.6 \pm 22.9$ & $16.7 \pm 5.0$ & $7.98 \pm 3.84$ & $17.0 \pm 6.6$ \\
\hline $\begin{array}{l}\text { Humsjön } \\
11\end{array}$ & $\begin{array}{l}12.72 \\
59.58\end{array}$ & 0.26 & $3.1 \pm 0.7$ & $8.7 \pm 3.2$ & $6.8 \pm 0.1$ & $4.5 \pm 0.4$ & $0.15 \pm 0.01$ & $0.09 \pm 0.02$ & $20.4 \pm 9.5$ & $9.9 \pm 2.2$ & $0.93 \pm 0.46$ & $6.9 \pm 1.8$ \\
\hline $\begin{array}{l}\text { Härsvatten } \\
12\end{array}$ & $\begin{array}{l}12.03, \\
58.02\end{array}$ & 0.19 & $10.7 \pm 2.9$ & $10.0 \pm 1.7$ & $4.6 \pm 0.2$ & $6.3 \pm 1.4$ & $<0.01 \pm 0.02$ & $0.13 \pm 0.04$ & $42.8 \pm 19.8$ & $5.0 \pm 3.0$ & $0.03 \pm 0.19$ & $2.1 \pm 1.0$ \\
\hline $\begin{array}{l}\text { Jutsajaure } \\
13\end{array}$ & $\begin{array}{l}19.94 \\
67.06\end{array}$ & 1.12 & $3.6 \pm 0.7$ & $7.3 \pm 3.4$ & $6.7 \pm 0.1$ & $1.8 \pm 0.1$ & $0.09 \pm 0.01$ & $0.02 \pm 0.01$ & $16.6 \pm 13.1$ & $9.8 \pm 2.9$ & $1.31 \pm 0.46$ & $7.3 \pm 4.1$ \\
\hline $\begin{array}{l}\text { Mäsen } \\
14\end{array}$ & $\begin{array}{l}12.55 \\
57.26\end{array}$ & 0.43 & $3.7 \pm 0.7$ & $9.7 \pm 3.0$ & $6.7 \pm 0.1$ & $4.8 \pm 0.4$ & $0.18 \pm 0.01$ & $0.14 \pm 0.02$ & $12.8 \pm 7.2$ & $12.3 \pm 4.2$ & $0.76 \pm 0.22$ & $7.7 \pm 1.1$ \\
\hline $\begin{array}{l}\text { Remmarsjön } \\
15\end{array}$ & $\begin{array}{l}18.27 \\
63.86\end{array}$ & 1.37 & $2.3 \pm 0.5$ & $5.6 \pm 2.5$ & $6.4 \pm 0.2$ & $2.1 \pm 0.2$ & $0.06 \pm 0.02$ & $0.04 \pm 0.01$ & $12.1 \pm 6.5$ & $10.6 \pm 3.5$ & $3.52 \pm 0.73$ & $10.5 \pm 1.4$ \\
\hline $\begin{array}{l}\text { Rotehogstjärnen } \\
16\end{array}$ & $\begin{array}{c}11.61 \\
58.82\end{array}$ & 0.17 & $2.1 \pm 0.5$ & $7.7 \pm 2.6$ & $5.3 \pm 0.3$ & $5.3 \pm 1.1$ & $<0.01 \pm 0.01$ & $0.11 \pm 0.04$ & $25.3 \pm 12.0$ & $12.4 \pm 3.1$ & $4.95 \pm 1.67$ & $13.2 \pm 2.6$ \\
\hline $\begin{array}{l}\text { Skärgölen } \\
17\end{array}$ & $\begin{array}{l}16.23 \\
58.76\end{array}$ & 0.16 & $3.9 \pm 1.0$ & $9.2 \pm 2.8$ & $6.7 \pm 0.1$ & $5.6 \pm 0.5$ & $0.16 \pm 0.01$ & $0.18 \pm 0.04$ & $10.1 \pm 6.4$ & $8.6 \pm 3.3$ & $0.85 \pm 0.39$ & $7.5 \pm 1.8$ \\
\hline $\begin{array}{l}\text { Stora Skärsjön } \\
18\end{array}$ & $\begin{array}{l}15.08 \\
57.12\end{array}$ & 0.31 & $3.7 \pm 0.8$ & $10.4 \pm 2.1$ & $6.7 \pm 0.1$ & $8.0 \pm 0.7$ & $0.14 \pm 0.02$ & $0.19 \pm 0.03$ & $35.4 \pm 23.9$ & $9.3 \pm 3.9$ & $0.71 \pm 0.58$ & $5.1 \pm 2.4$ \\
\hline $\begin{array}{l}\text { Stensjön } \\
19\end{array}$ & $\begin{array}{l}14.77 \\
56.45\end{array}$ & 0.57 & $2.8 \pm 0.6$ & $7.8 \pm 2.4$ & $6.4 \pm 0.1$ & $1.8 \pm 0.2$ & $0.05 \pm 0.01$ & $0.05 \pm 0.01$ & $9.5 \pm 3.2$ & $8.2 \pm 3.0$ & $1.71 \pm 0.47$ & $6.5 \pm 0.8$ \\
\hline $\begin{array}{l}\text { Storasjö } \\
20\end{array}$ & $\begin{array}{l}15.27 \\
56.95\end{array}$ & 0.38 & $2.6 \pm 1.2$ & $9.2 \pm 4.3$ & $5.6 \pm 0.3$ & $3.4 \pm 0.6$ & $<0.01 \pm 0.01$ & $0.09 \pm 0.04$ & $20.3 \pm 15.1$ & $13.2 \pm 4.6$ & $3.53 \pm 2.02$ & $10.3 \pm 2.9$ \\
\hline $\begin{array}{l}\text { Stora Envättern } \\
21\end{array}$ & $\begin{array}{l}17.35 \\
59.11\end{array}$ & 0.38 & $4.1 \pm 1.0$ & $9.9 \pm 1.6$ & $6.5 \pm 0.1$ & $4.2 \pm 0.4$ & $0.06 \pm 0.01$ & $0.14 \pm 0.03$ & $11.9 \pm 7.8$ & $8.9 \pm 3.3$ & $0.90 \pm 0.42$ & $9.4 \pm 3.5$ \\
\hline $\begin{array}{l}\text { Stor-Tjulträsket } \\
22\end{array}$ & $\begin{array}{l}16.07 \\
65.96\end{array}$ & 5.43 & $9.2 \pm 1.2$ & $8.3 \pm 2.9$ & $7.3 \pm 0.1$ & $4.1 \pm 0.3$ & $0.30 \pm 0.03$ & $0.05 \pm 0.01$ & $12.5 \pm 4.6$ & $6.3 \pm 4.6$ & $0.28 \pm 0.13$ & $2.3 \pm 0.9$ \\
\hline $\begin{array}{l}\text { Sännen } \\
23\end{array}$ & $\begin{array}{l}15.37 \\
56.32\end{array}$ & 1.12 & $3.8 \pm 1.1$ & $9.3 \pm 2.4$ & $6.1 \pm 0.2$ & $7.2 \pm 0.8$ & $0.03 \pm 0.01$ & $0.29 \pm 0.05$ & $24.4 \pm 15.6$ & $12.5 \pm 3.3$ & $0.91 \pm 0.39$ & $6.9 \pm 1.3$ \\
\hline $\begin{array}{l}\text { Tväringen } \\
24\end{array}$ & $\begin{array}{l}15.68 \\
62.24\end{array}$ & 1.76 & $3.6 \pm 0.5$ & $7.1 \pm 3.0$ & $6.7 \pm 0.1$ & $2.5 \pm 0.2$ & $0.12 \pm 0.02$ & $0.05 \pm 0.01$ & $9.4 \pm 4.0$ & $8.4 \pm 4.1$ & $1.56 \pm 0.66$ & $7.5 \pm 1.3$ \\
\hline $\begin{array}{l}\text { Älgarydssjön } \\
25\end{array}$ & $\begin{array}{l}14.76 \\
57.11\end{array}$ & 0.35 & $1.9 \pm 1.3$ & $8.5 \pm 2.6$ & $5.7 \pm 0.3$ & $4.9 \pm 0.8$ & $0.01 \pm 0.01$ & $0.12 \pm 0.05$ & $42.0 \pm 37.9$ & $18.3 \pm 7.0$ & $5.01 \pm 3.47$ & $14.8 \pm 6.4$ \\
\hline $\begin{array}{l}\text { Övre Skärsjön } \\
26\end{array}$ & $\begin{array}{l}15.55 \\
59.84\end{array}$ & 1.74 & $3.9 \pm 0.7$ & $8.7 \pm 2.0$ & $5.6 \pm 0.2$ & $2.9 \pm 0.4$ & $<0.01 \pm<0.01$ & $0.12 \pm 0.03$ & $17.2 \pm 5.4$ & $6.2 \pm 2.5$ & $1.99 \pm 0.70$ & $7.1 \pm 1.1$ \\
\hline
\end{tabular}

